\title{
INVESTIGATING THE INFLUENCE OF POLYDIMETHYLSILOXANE (PDMS) CROSSLINKING CONTENT ON MEMBRANE SELECTIVITY
}

\author{
Osama Farid ${ }^{1,2}$, Abdul Rehman Memon ${ }^{2}$, John Robinson ${ }^{2}$, and Steve Tarleton ${ }^{3}$ \\ 1 Reactors Department, Atomic Energy Authority of Egypt, Cairo, Egypt \\ 2 Department of Chemical and Environmental Engineering, University of Nottingham, Nottingham, UK \\ 3 Department of Chemical Engineering, Loughborough University, Loughborough, UK \\ Email: usamafa98@hotmail.co.uk
}

\begin{abstract}
Polymer crosslinking has significant importance in the relevant retrofitting of the microstructure of polymer network in terms of polymer swelling, membrane performance and its stability. This research focused on investigating the sorption influence on membrane selectivity in terms of measuring swelling of polydimethylsiloxane (PDMS) at varying polymer crosslinking in alcohol/water solutions. ATR-FTIR spectra for different crosslinked PDMS were obtained using Nicolet FTIR Spectrometer, and solvent concentration was determined by refractometer. The experimental results transpired that swelling degree decreased with increasing crosslinking content, which led to a more rigid polymer network structure resulting in less free volume as well as reduced absorbed liquid in the polymer. The addition of crosslinker resulted in the reduction of PDMS hydrophobicity influencing the sorption of alcohol into the polymer. It was found that PDMS at all crosslinking contents was selective towards ethanol and isopropanol and that addition of the crosslinker at concentrations at or below $10 \%$ led to the existence of vinyl and/or Si-H groups in the network. The sorption coefficient for isopropanol was also found to be higher than that of ethanol at all crosslinking contents, with increasing crosslinking content resulted in increased sorption coefficient.
\end{abstract}

Keywords: Alcohol sorption, Membrane, Polymer microstructure, Polydimethylsiloxane (PDMS), Crosslinking content, Sorption.

\section{INTRODUCTION}

Nanofiltration has many potential applications as a separation technology for processes that use mixtures of aqueous and organic solvents, such as alcohol/water mixtures. For separation of these organics as an end-of-pipe treatment, membranes are more likely where process volumes are less than $50000 \mathrm{gal}\left(190 \mathrm{~m}^{3}\right)$ per day [1]. Membrane separation is a proven technology that is used with a high efficiency in aqueous media, whereas it is characterized by its slower rate of uptake in aqueous/organic mixtures. This slow behavior could be attributed to the interaction between membrane and solvent(s) that limits both the permeability and selectivity of the membrane [2]. The determination of waste/membrane interactions, permeability, selectivity, and swelling characteristics of the membrane is necessary. Membrane swelling plays a key role in the transport of molecules through membranes, as swelling changes the physical and chemical structure of the polymer. 
Previous studies have shown the importance of membrane swelling in transport processes through NF membranes [3-4].Swelling is a thermodynamic phenomenon in which a solvent transfers from a liquid phase to a polymer phase, and deformation of the polymer network occurs as a result. The swollen material can be considered to be a mixture of solvent and polymer, and the thermodynamics of liquid mixtures can be extended to swollen polymers [5]. Swelling of dense polymers leads to an increase in the free volume. The membrane becomes more open and allows more liquid to move through, which influences both permeability and selectivity. However swelling of porous membranes leads to contraction of the pores walls and pores becoming more narrow, which enhances selectivity but decreases permeability [6].

It is postulated that the membrane swells, the polymer chains are stretched and the free volume in the space between them increases hence increasing solvent permeability [7]. Researchers examined the swelling of many different NF membranes with several species, in both aqueous and non-aqueous systems. Tarleton et al. [7] observed NF membrane swelling with organic solvents, such as methanol, ethanol, propanol, and $\mathrm{n}$-heptanes. They postulated that swelling increases the free volume within the membrane, which can be interpreted as an induced pore-like structure or raised membrane porosity. They suggested that poor-swelling solvents yield a lower flux and higher solute rejection than good-swelling solvents. They conclude that the degree of polymer swelling governs the transport regions within the membrane, and hence, the overall solvent flux and solute rejection characteristics. Robinson et al. [3] examined flux of organic solvents through
polydimethylsiloxane(PDMS) membrane for n-alkanes, i-alkanes and cyclic compounds. They showed that swelling is a good indicator of permeation. Due to swelling, so-called channels are formed and the solvent flux increases. Verhoef et al. [6] investigated prevaporation of ethanol/water mixtures through a hydrophobic membrane. They suggested that the difference between NF and prevaporation membranes is explained by the influence of swelling, and the different interactions between permeating molecules and the membrane. Mohammadi et al. [8] measured the swelling degree of PDMS in alcohol/water binary mixtures as a function of alcohol concentration. They showed that the swelling degree of PDMS in ethanol/water is higher than the swelling degree in methanol/water, and concluded that selectivity of a membrane is mainly governed by the sorption component. Yeom et al. [9] used the degree of polymer swelling to assess the membrane selectivity in ethanol/water mixture. In the case of a highly swollen membrane, the membrane pores was influenced and hence transported through the membranes. Farid and Robinson [10] studied removal of alcohols (ethanol and isopropanol) from water using PDMS as an example of hydrophobic material, and concluded that a nonlinear relation existed between sorption and alcohol concentration in the swollen polymer.

Polymer swelling influenced by the microstructure of the polymer network, improvements of polymer swelling can be accomplished by modifying the conditions of its preparation, including crosslinking content. Crosslinking is the connection of polymer chains to form one network. Crosslinking changes the physical and chemical structure of the polymer, as the addition of more crosslinker to the polymer main chain changes the 
microstructure of the polymer network, making the polymer stronger and more rigid. Moreover, the addition of more cross-linker reduces membrane free volume and changes membrane hydrophobicity/hydrophilicity. Polymer crosslinking therefore affects membrane performance and stability [11-12]. Membrane swelling characteristics have an impact on membrane rejection. Rejection is not governed by a single mechanism, rather, it is a contribution of different mechanisms, a contribution which occurs through several mechanisms:

- Size exclusion: molecules are too large to enter the transport region within the membrane.

- Surface repulsion: molecules can be repelled due to hydrophobic/hydrophilic interactions with membrane materials or electrostatic forces.

- Sorption: the membrane surface absorbs one or more molecules selectively.

In this work, PDMS polymers swelling in solvent mixture is used to assess the solventpolymer interaction at different polymer crosslinking, and investigates the influence of sorption alone on membrane selectivity. For this purpose an experimental system was designed to measure swelling of PDMS polymers at different polymer crosslinking in ethanol/water and isopropanol/water solvents.

\section{MATERIALS AND METHODS}

\subsection{MATERIALS}

PDMS was manufactured by a cross-linking reaction between two Room Temperature Vulcanizing silicone components namely; prepolymer (RTV615A) and crosslinker(RTV615B). These two clear liquid compounds were provided by TECHSIL Ltd. RTV615A consists mainly of long PDMS oligomers capped by vinyl groups, and RTV615B consists of shorter PDMS oligomers with silane functional groups [13].

\subsection{PREPARATION OF PDMS SAMPLES}

RTV615A was mixed for 5 minutes with RTV615B components using clean glass tools, the process was performed in a container 4-5 times larger than the volume of the reactant. The sides and bottom of the container were carefully scraped to achieve a homogeneous mixture. Excessive mixing speeds were avoided, as this could entrap large amounts of air or cause overheating of the mixture. The mixed PDMS was poured into the glass mould. The glass containing the polymer was put in an oven, and the final mixture was allowed to cure at $60^{\circ} \mathrm{C}$ for 6 hours. The PDMS samples were prepared in dense blocks to allow measurement of swelling equilibrium. The blocks were then cut to size, $15 \mathrm{~mm}$ (diameter) and $10 \mathrm{~mm}$ (length), in order to measure the swelling abilities in a solvent or mixture of solvents. This procedure was repeated to prepare different samples with different cross linking degrees of 5, 10, 15, 20, and $25 \mathrm{wt} \%$. The degree of cross linking was calculated using the following equation:

crosslinking content $=$

$\frac{\text { weight of RTV615B }}{\text { (weight of RTV615B + weight of RTV615A) }} \%$

\subsection{Characterization}

Attenuated Total Reflectance -Fourier Transform InfraRed spectroscopy (ATRFTIR) analysis was used to characterize the reactants and product of the cross-linking process. The analysis was conducted using A Nicolet 6700 ATR-FTIR spectrometer with $\mathrm{ZnSe}$ crystal, where samples were kept in direct contact with the ATR crystal. by using a pressure arm that was positioned over the sample area and the applied force pushed the sample into the diamond surface [14]. 


\subsection{SWELLING MEASUREMENTS}

The polymer was pre-weighed and immersed in a bottle containing 30\% alcohol/water at liquid to solid ratio of 5 . The samples were weighed, and the experiments were carried out at ambient temperature. After being taken out of the sealed bottle the polymer sample was weighed, and then replaced in the bottle until the swollen weight reached equilibrium. The swelling degree at equilibrium (SD \%) is expressed as a percentage according to Equation 2.

$\mathrm{SD} \%=\left(\frac{\mathrm{m}_{\mathrm{fp}}-\mathrm{m}_{\mathrm{ip}}}{\mathrm{m}_{\mathrm{ip}}}\right) \times 100$

Where $\mathrm{m}_{\mathrm{fp}}$ and $\mathrm{m}_{\mathrm{ip}}$ are final and initial mass of the polymer, respectively.

\subsection{SORPTION EXPERIMENTS}

Sorption was based on batch experiments, where the solvent concentration was determined using the refractive index (RI) measurement technique, which is based on the change in RI of a binary solvent mixture as a function of solvent concentration. Experiments were performed using a refractometer (Mettler Toledo Refractometer $30 \mathrm{PX})$ at a temperature of $20^{\circ} \mathrm{C}$. Calibration curves were prepared, and used for mass balance calculations. Solvent concentration in the remaining liquid was calculated from a calibration curve, and the corresponding solvent concentration in the swollen polymer was calculated using a mass balance. The mass balance was based on equilibrium between polymer and solvent mixtures.

\section{RESULTS AND DISCUSSION}

\subsection{ATR-FTIR CHARACTERIZATIONS}

The infrared spectra of the reactants are shown in Figure 1(a), IR spectrum of RTV615A contains siloxane group ( $\mathrm{Si}-\mathrm{O}-\mathrm{Si}$ ), methyl $\left(-\mathrm{CH}_{3}\right)$, methyl-silicone groups ( $\mathrm{Si}-$ $\left.\mathrm{CH}_{3}\right)$, and vinyl group $\mathrm{Si}-\mathrm{CH}=\mathrm{CH}_{2}[15]$.
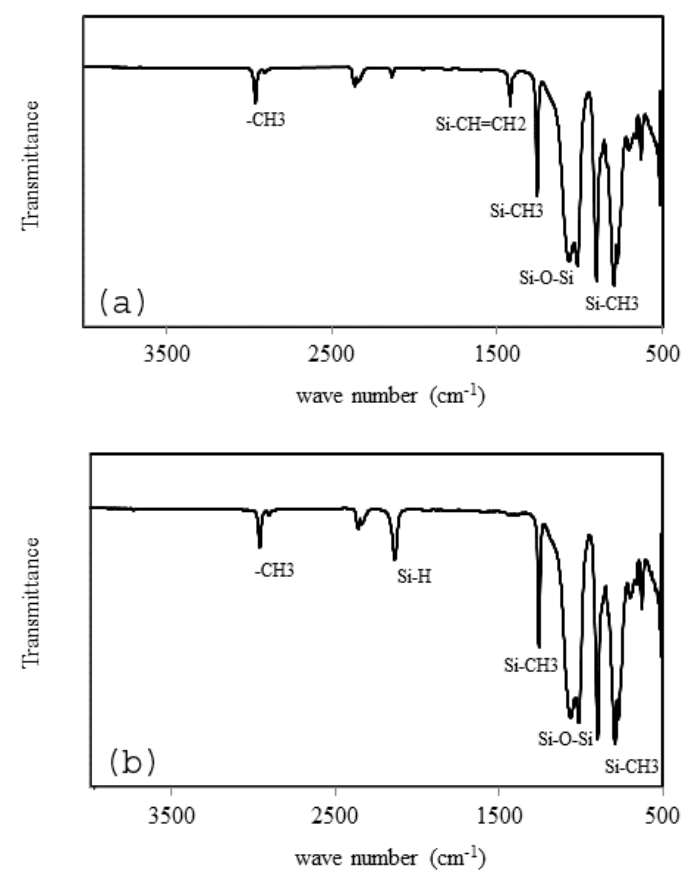

Fig. 1. Fourier Transform infrared spectra of the reactants (a) prepolymer RTV615A, (b) cross-linker RTV615B

Figure 1(b) presents the infrared spectra of RTV 615B. It is noted that the vinyl group ( $\mathrm{Si}-\mathrm{CH}=\mathrm{CH}_{2}$ ) is absent and the addition of a $\mathrm{Si}-\mathrm{H}$, which acts as the functional crosslinker [16].

The FTIR spectra can be used to verify that RTV615A and RTV615B are both silicone components which contain the functional groups necessary to form cross-linked PDMS. The results indicate that no other additives were detected in either the pre-polymer or the crosslinker, and confirm the purity of the substances used.

ATR-FTIR spectra for products were investigated, as shown in Figure 2. The ATRFTIR spectra contains several expected peaks which correspond to the pre-polymer and crosslinking agent. The vinyl groups act as a cross-linking functional group in the prepolymer, and the changes in the intensity of this peak can be attributed to the consumption of vinyl groups due to increasing cross-linking content. The spectra confirm that a hydrosilylation reaction occurs 
between $\mathrm{Si}-\mathrm{H}$ groups at each end of the crosslinker, where it reacts with the $\mathrm{C}=\mathrm{C}$ bond of the pre-polymers to obtain epoxidized PDMS. Cross-linking reaction depends on the amount of both RTV615A and RTV615B in the reaction mixture. By varying their ratios different PDMS will be formed. The IR spectrum for the PDMS samples prepared with a cross-linker content of 5\% shows a peak at $1480 \mathrm{~cm}^{-1}$, indicating that there is still an excess of vinyl groups still in the final polymer sample. For polymer samples prepared with $10,15,20$, and $25 \%$ crosslinker content there are no apparent peaks at $1480 \mathrm{~cm}^{-1}$, suggesting that the vinyl groups have completely reacted.

The Si-H absorption peak cannot be clearly detected for the polymer samples prepared at 5 and $10 \%$ cross-linker content. This indicates that all of the $\mathrm{Si}-\mathrm{H}$ groups were consumed during the cross-linking reaction at these compositions. For 15, 20, and 25\% cross-linker the changes in the intensity of Si$\mathrm{H}$ groups were due to the addition of excess cross-linker, leading to an excess of $\mathrm{Si}-\mathrm{H}$ groups in the final polymer samples after the cross-linking reaction. Figure 3 shows a schematic for the cross-linking reaction (hydrosilylation), which depends on the ability of the hydrosilane bond of the crosslinker $(\mathrm{Si}-\mathrm{H})$ to add a cross carbon-carbon double bond that belongs to the pre-polymer, forming Si- $\mathrm{CH}_{2}-\mathrm{CH}_{2}-\mathrm{Si}$ linkages [17]. The multiple reaction sites on both the prepolymer and cross-linker oligomers allow for three-dimensional cross-linking [18]. If the ratio of cross-linker to pre-polymer is increased, a harder, more cross-linked PDMS results are obtained.

The red and blue coloured lines in Figure 3 shows the linkage, cross-linking the polymer chains and connecting them together to form one network.

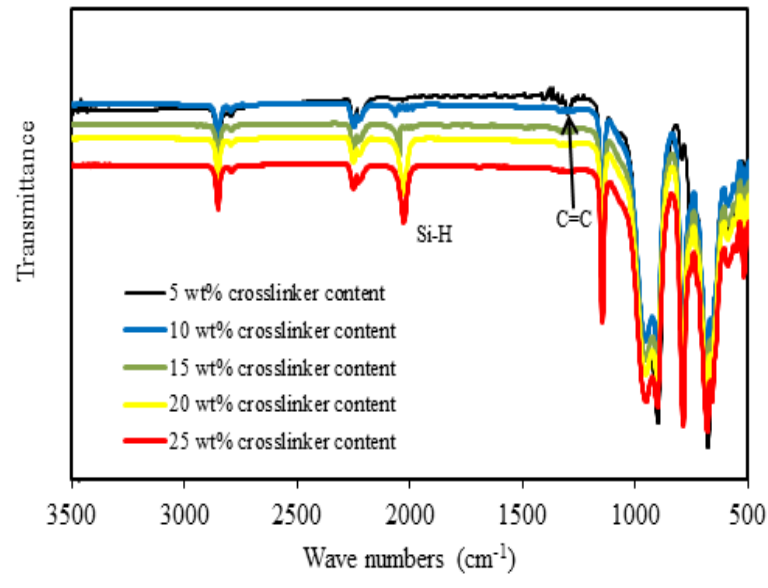

Fig. 2. ATR-FTIR spectra of different cross-linked PDMS soluble PDMS pre-polymer
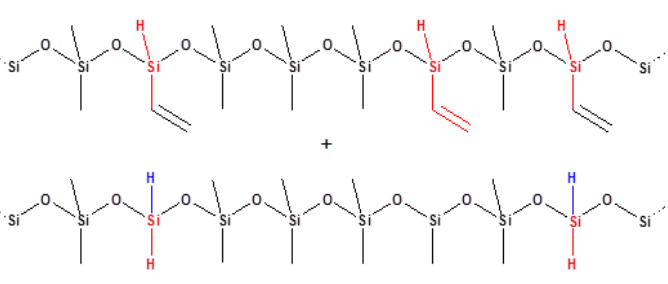

soluble PDMS cross-linker

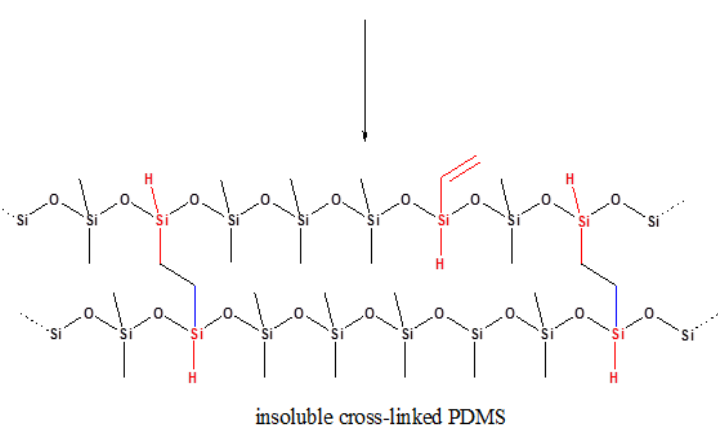

Fig. 3.Schematic illustrating cross-linking reaction of PDMS. Reaction of the Si-H with $\mathrm{C}=\mathrm{C}$ bond to form the new Si-C bond $(-)$.

This connection could occur at any point along the polymer chain, so the structure in Figure 3 does not necessarily represent that which would be obtained for every crosslinking reaction.

Figure 3 shows that PDMS network is a blend of unreacted PDMS oligomers (still containing vinyl and/or Si-H groups) and fully-cured PDMS (without unreacted groups). The findings suggest that the addition of the crosslinker at concentrations at or below $10 \%$ leads to the existence of vinyl and/or Si-H groups in the PDMS network. 
In order to investigate the degree of crosslinking this study deviated from the advice of the manufacturer, which was to use a 10/1 ratio of RTV615A/RTV615B [13]. The validity of this approach was investigated by characterising the resulting polymers using ATR-FTIR. In order to quantify the different crosslinking content the peak areas of the hydrosilane group $(-\mathrm{Si}-\mathrm{H})$ at $2060 \mathrm{~cm}^{-1}$, and the methyl-silicone groups $\left(-\mathrm{Si}_{-}-\mathrm{CH}_{3}\right)$ at $2960 \mathrm{~cm}^{-1}$ were evaluated. The $\mathrm{Si}-\mathrm{CH}_{3}$ groups do not take part in the crosslinking reaction, therefore their peak areas were used as a standard [19]. However, the Si-H peak area increases with increasing crosslinker content, and this peak was used to verify the degree of crosslinking.

The peak areas for RTV615A and RTV615B were evaluated before the crosslinking reaction took place. In RTV615A the Si-H peak area and $\mathrm{Si}-\mathrm{CH}_{3}$ peak area are 2.1 and 58.2 respectively, and the corresponding $\mathrm{Si}$ $\mathrm{H} / \mathrm{CH}_{3}$ area ratio is 0.03 . In RTV615B the ratio is 0.75 . The crosslinking reactions reduce the peak area of $\mathrm{Si}-\mathrm{H}$ in the final polymer, which can be calculated according to Equation 3 [19].

\section{Crosslinked area $=$}

$\mathrm{Q}_{\mathrm{RTV615B}}$ (crosslinking ratio) $+\mathrm{Q}_{\mathrm{RTV615A}}(1-$ crosslinking ratio)

where $\mathrm{Q}$ is the ratio between the $\mathrm{Si}-\mathrm{H}$ peak area and the $\mathrm{Si}-\mathrm{CH}_{3}$ peak area. The Si$\mathrm{H} / \mathrm{CH}_{3}$ ratio obtained from FTIR was used in conjunction with Equation 3 to quantify the crosslinking content in the polymer as shown in Table 1.

The data in Table 1 shows that increasing the cross-linker content from 5 to $25 \%$ results in the corresponding cross-linking content in the PDMS increasing from 4.7 to $19.8 \mathrm{wt} \%$. The results show that PDMS polymers prepared with 5 and $10 \%$ cross-linker contained a negligible amount of unreacted cross-linker in the final polymer. Polymers prepared at 15 , 20 and $25 \%$ contained unreacted crosslinking agent and hence the polymer was a mixture of cross-linked PDMS and crosslinking agent. This result is in agreement with Lue et al. [19], who also used FTIR to verify the cross-linking content of PDMS. They concluded that PDMS made with 9 wt $\%$ cross-linking agent contained a negligible amount of unreacted cross-linker, whereas PDMS prepared with $20 \mathrm{wt} \%$ cross-linker resulted in a final polymer with $15 \mathrm{wt} \%$ crosslinking.

\subsection{Swelling CHARACTERISTICS OF PDMS SAMPLES}

In order to validate the technique used in this study, the experimental results were compared to those reported by Stafie et al. [21]. They prepared PDMS with different cross-linker content by changing the ratio of RTV615A to RTV615B, 10/0.7, $10 / 1$ and 10/2, corresponding to a crosslinker content of 6.5 , 9.1 , and $16.7 \%$ respectively. Their data were compared with the swelling data obtained in this work and the results shown in Figure 4.

TABLE 1: PEAK AREA AND RATIO FOR PDMS OF VARYING CROSS-LINKER CONTENT

\begin{tabular}{|c|c|c|c|c|c|c|}
\hline $\begin{array}{l}\text { Nominal cross- } \\
\text { linking degree } \\
(w t \%)\end{array}$ & $\begin{array}{l}\text { Area before cross- } \\
\text { linking }\end{array}$ & $\begin{array}{c}\text { Peak area at } 2060 \\
\mathrm{~cm}^{-1}\end{array}$ & $\begin{array}{c}\text { Peak area at } \\
2960 \mathrm{~cm}^{-1}\end{array}$ & $\begin{array}{c}\mathrm{Si}-\mathrm{H} / \mathrm{CH}_{3} \text { area } \\
\text { ratio }\end{array}$ & $\begin{array}{c}\text { Reduction in } \\
\mathrm{Si}-\mathrm{H} / \mathrm{CH}_{3}\end{array}$ & $\begin{array}{l}\text { Actual crosslinking degree } \\
\qquad(\mathrm{wt} \%)\end{array}$ \\
\hline 5 & 6 & 1.2 & 301.0 & 0.0030 & 0.95 & 4.7 \\
\hline 10 & 10 & 2.4 & 309.5 & 0.0070 & 0.93 & 9.4 \\
\hline 15 & 14 & 6.3 & 315.2 & 0.0199 & 0.87 & 13.1 \\
\hline 20 & 17 & 11.0 & 328.6 & 0.0335 & 0.82 & 16.4 \\
\hline 25 & 21 & 18.0 & 396.5 & 0.0443 & 0.79 & 19.8 \\
\hline
\end{tabular}




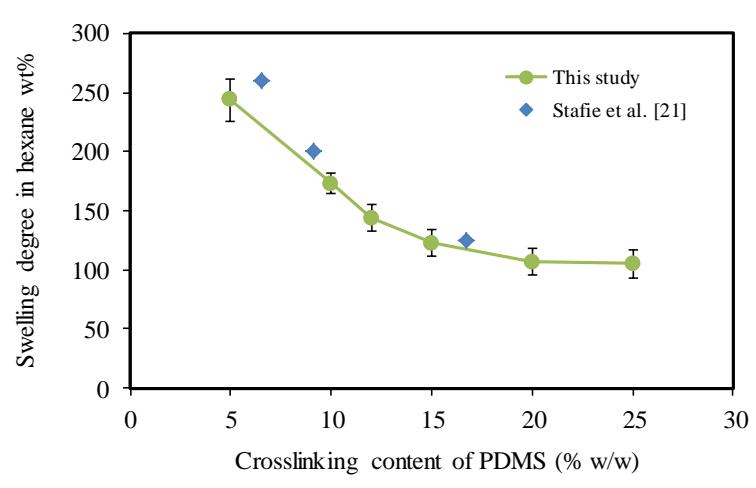

Fig.4. Relationship between swelling degree of PDMS in hexane at different crosslinking content, and comparison with literature

The results indicate that swelling degree decreases with increasing cross-linking content for both trends. Increasing crosslinking content leads a more rigid polymer network structure, which makes the polymer matrix more rigid. This in turn results in less free volume, which might reduce the amount of absorbed liquid in the polymer. The two studies show a good quantitative agreement.

\subsection{EFFECT OF CROSS-LINKING CONTENT ON ALCOHOL SORPTION}

The swelling equilibrium studies were also extended to investigate alcohol concentration within the liquid inside the swollen polymer. PDMS samples of varying cross-linking content were immersed in flasks containing alcohols in water. Solvent concentration in the remaining liquid was calculated from a calibration curve, and the corresponding solvent concentration in the swollen polymer was calculated using a mass balance. The mass balance was based on the equilibrium between polymer and solvent mixtures, and the composition of the swollen polymer in ethanol/water and isopropanol/water are shown in Tables 2 and 3 respectively.

The results in Tables 2 and 3 show the composition of the swollen PDMS at different cross-linking contents. The contribution of PDMS in the swollen polymer can be excluded and the results interpreted in terms of the alcohols/water
TABLE 2: ETHANOL, WATER AND PDMS CONCENTRATIONS IN THE SWOLLEN POLYMER

\begin{tabular}{|c|c|c|c|}
\hline $\begin{array}{c}\text { PDMS } \\
\text { cross- } \\
\text { linking } \\
\text { content } \\
\text { (wt\%) }\end{array}$ & $\begin{array}{c}\text { Ethanol } \\
\text { concentration in } \\
\text { swollen polymer } \\
\text { (wt\%) }\end{array}$ & $\begin{array}{c}\text { Water } \\
\text { concentration } \\
\text { in swollen } \\
\text { PDMS (wt\%) }\end{array}$ & $\begin{array}{c}\text { PDMS } \\
\text { concentration } \\
\text { in swollen } \\
\text { polymer (wt\%) }\end{array}$ \\
\hline 5 & 11.2 & 16.6 & 72.2 \\
\hline 10 & 11.6 & 15.3 & 73.0 \\
\hline 15 & 12.0 & 14.0 & 74.0 \\
\hline 20 & 12.4 & 12.4 & 75.2 \\
\hline 25 & 13.0 & 12.5 & 74.5 \\
\hline
\end{tabular}

TABLE 3: ISOPROPANOL, WATER AND PDMS

CONCENTRATIONS IN THE SWOLLEN POLYMER

\begin{tabular}{|c|c|c|c|}
\hline $\begin{array}{c}\text { PDMS } \\
\text { cross- } \\
\text { linking } \\
\text { content } \\
\text { (wt\%) }\end{array}$ & $\begin{array}{c}\text { Isopropanol } \\
\text { concentration in } \\
\text { swollen polymer } \\
\text { (wt\%) }\end{array}$ & $\begin{array}{c}\text { Water } \\
\text { concentration in } \\
\text { swollen PDMS } \\
\text { (wt\%) }\end{array}$ & $\begin{array}{c}\text { PDMS } \\
\text { concentration in } \\
\text { swollen polymer } \\
\text { (wt\%) }\end{array}$ \\
\hline 5 & 14.2 & 13.7 & 72.0 \\
\hline 10 & 14.8 & 13.2 & 72.1 \\
\hline 15 & 15.3 & 12.4 & 72.3 \\
\hline 20 & 15.8 & 11.3 & 72.9 \\
\hline 25 & 16.0 & 10.6 & 73.4 \\
\hline
\end{tabular}

ratio. The results indicate that alcohol concentration within swollen polymer increases with increasing crosslinking.

This behaviour is expected because the PDMS network becomes more rigid, resulting in less free volume, and reduced alcohol and water sorption into the polymer matrix. The addition of crosslinker also reduces the hydrophobicity of PDMS, which influences the sorption of alcohol (ethanol or isopropanol from its mixtures) into the polymer. Alcohol concentration from aqueous alcohol mixtures within the liquid in the swollen polymer are presented in Figure 5.

Figure 5 shows that the weight fraction of ethanol within the liquid absorbed in the polymer increases from 40.3 to $51.0 \%$ as the cross-linking content increases from 5 to $25 \%$. Over the same range of cross-linking content the corresponding isopropanol concentration increases from 51 to $60 \%$. 


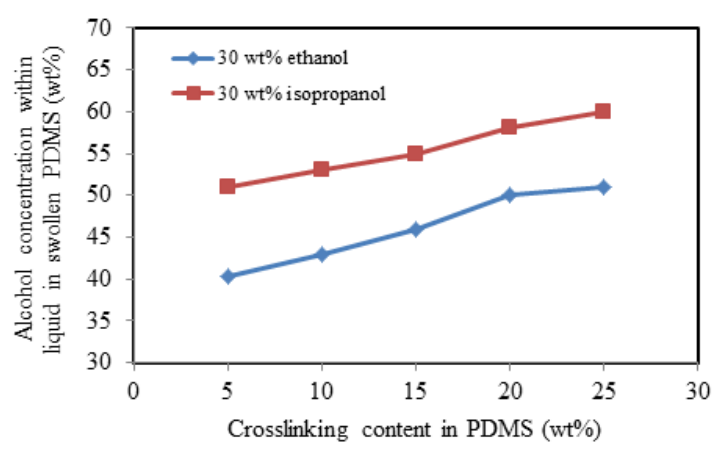

Fig.5. Effect of cross-linking content on alcohol sorption in swollen PDMS

The results show that isopropanol concentration within the liquid is higher than that of ethanol at all cross-linking contents. Both trends indicate that the alcohol concentration increases upon increasing the crosslinking content. The results illustrate that alcohol concentration within the liquid in the swollen polymer is higher than the initial alcohol concentration, and indicates an alcohol-rich PDMS polymer. Although increasing crosslinking tends to degrease swelling degree, polymer absorbs more alcohol than water, which makes it alcohol selective. Summarising the above results it can be seen that PDMS, at all cross-linking contents investigated is selective towards alcohol. This result points to the potential ability to alter the selectivity of PDMS for ethanol and isopropanol extraction in a separation process for aqueous solutions. For the extraction of ethanol and isopropanol from water, the required selectivity could be adjusted by changing the cross-linking content of the prepared polymer.

\subsection{ALCOHOL SORPTION COEFFICIENT}

Composition studies were also extended to investigate the alcohol sorption coefficient at different crosslinking contents. The membrane selectivity is composed of sorption selectivity, and diffusion selectivity [22]. The selectivity of a membrane is strongly influenced by two factors: the sorption of one (or more) component(s) of

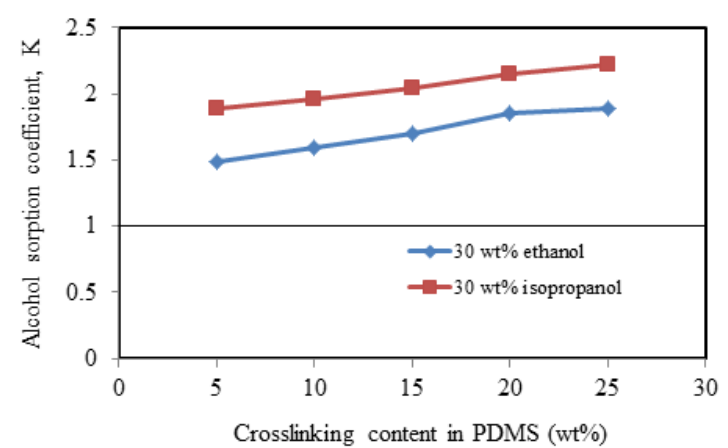

Fig. 6. Relation between cross-linking content and alcohol sorption coefficient for ethanol/water

the feed into the membrane, and the ease of diffusion of the permeating molecules through the membrane. If there is no selectivity due to sorption there will be no selectivity due to diffusion[23]. The

sorption coefficient $\mathrm{K}_{\mathrm{i}}[24]$ can be calculated by equation:

$\mathrm{K}_{\mathrm{i}}=\frac{\mathrm{C}_{\mathrm{ip}}}{\mathrm{C}_{\mathrm{is}}}$

Where $\mathrm{C}_{\mathrm{is}}$ is the equilibrium molar concentration of component $\mathrm{i}$ in the liquid mixture, and $\mathrm{C}_{\mathrm{ip}}$ is final equilibrium molar concentration of $\mathrm{i}$ within the liquid at the polymer side. The boundary conditions for sorption coefficient $(\mathrm{Ki})$ is Sorption coefficient $(\mathrm{Ki})>1$, shows that membrane preferentially absorb solvent Sorption coefficient $(\mathrm{Ki})<1$, shows that membrane does not selectivity absorb the solventSorption coefficient $(\mathrm{Ki})=1$ no membrane selectivity .

The sorption coefficients of ethanol in ethanol/water mixture and isopropanol in isopropanol/water mixtures are shown in Figure 6.

The results show that the sorption coefficient for isopropanol is higher than that of ethanol at all crosslinking contents. This is expected because the swelling degree in isopropanol is higher than that in ethanol. Both trends indicate that sorption coefficient increases with increasing cross-linking content. Over the 5 to $25 \%$ range, sorption coefficients for ethanol rise from 1.49 to 1.88 , 
and for isopropanol from 1.89 to 2.22. The results demonstrate that sorption coefficients are a function of polymer cross-linking. Even though water is smaller molecules compared to alcohol, and ethanol is smaller compared to isopropanol, there is selective sorption of alcohol over water and the sorption coefficient of the Isopropoanol is larger compared to the ethanol. This behaviour could be attributed to the polarity of alcohol as the higher the polarity of molecule, the lower the sorption coefficient.

Nguyen et al. [25-26] investigated the swelling and sorption properties of PDMS materials cross-linked under different conditions. They found an increase in ethyl acetate sorption in the swollen polymer due to increase PDMS cross-linking content, and attributed the difference in sorption of ethyl acetate from water to the addition of more cross-linker, which in their view led to reduced membrane free volume, and change the hydrophobicity/hydrophilicity of the polymer.

\section{CONCLUSION}

Increasing polymer cross-linking content decreases the degree of polymer swelling for PDMS aqueous alcohol solutions. The alcohol sorption is influenced by the addition of cross-linker to the polymer matrix, which reduces the polymer free volume through which molecules can be absorbed. The degree of crosslinking affects the sorption coefficient, the higher the level of crosslinking between the polymer chains, the more alcohol-selective PDMS polymers become, also PDMS presented a higher isopropanol sorption coefficient than that of ethanol. The study concluded that selectivity can be tailored by changing crosslinking content.

\section{REFERENCES}

[1] M. Cheryan, and N. Rajagopalan, "Membrane processing of oily streams. Wastewater treatment and waste reduction". Journal of Membrane Science, 1998. 151(1): pp. 13-28.

[2] J. P., Robinson, E. S., Tarleton, C. R., Millington, A., Nijmeijer, "Solvent flux through dense polymeric nanofiltration membranes". Journal of Membrane Science, 2004. 230(1-2): pp. 29-37.

[3] J.P. Robinson, E.S. Tarleton, C.R. Millington,, and A. Nijmeijer, "Solvent flux through dense polymeric nanofiltration membranes". Journal of Membrane Science, 2004. 230(1-2): pp. 29-37.

[4] N. Stafie, D.F. Stamatialis, and M. Wessling, "Insight into the transport of hexane-solute systems through tailor-made composite membranes". Journal of Membrane Science, 2004. 228(1): pp. 103-116.

[5] M. Badiger, A.K. Lele, M.G Kulkarni, and R.A. Mashelkar, "Swelling and phase transitions in deforming polymeric gels". Industrial \& Engineering Chemistry Research, 1994. 33(10): pp. 2426-2433.

[6] A. Verhoef, A. Figoli, L. Bram, B. Bettens, E. Drioli, and B. Van der Bruggen, "Performance of a nanofiltration membrane for removal of ethanol from aqueous solutions by pervaporation. Separation and Purification Technology", 2008. 60(1): pp. 54-63.

[7] E.S. Tarleton, J.P. Robinson, C.R. Millington, and A. Nijmeijer, "Non-aqueous nanofiltration: solute rejection in low-polarity binary systems". Journal of Membrane Science, 2005. 252(1-2): pp. 123-131.

[8] T. Mohammadi, A. Aroujalian, and A. Bakhshi, "Pervaporation of dilute alcoholic mixtures using PDMS membrane". Chemical Engineering Science, 2005. 60(7): pp. 1875-1880.

[9] C.K. Yeom and K.-H. Lee, "Pervaporation separation of water-acetic acid mixtures through poly(vinyl alcohol) membranes crosslinked with glutaraldehyde". Journal of Membrane Science, 1996. 109(2): pp. 257-265.

[10] O.M. Farid and J.P. Robinson, "Removal of organics from wastewater using nanofiltration". journal of filtration society, 2009. 9(4): p. 295300. 
[11] N.G. Mccrum, C.P. Buckley, and C.B. Bucknall, "Principles of polymer engineering ed". 2nd. 1997, oxford university oxford science pubications

[12] C.A. Dreiss, B. Terence, J. Natalie, J. Kilburn, D. Alam, M.A. Schmidt, and G.Gordon, "Effect of crosslinking on the mobility of PDMS filled with polysilicate nanoparticles: Positron lifetime, rheology and NMR relaxation studies". Polymer, 2007. 48(15): pp. 4419-4428.

[13] Jiang Huang, Shoujun Xiao, Marc A. Unger "Polymer surface modification", http://www.google.com/patents/US7005493, Feb. 2006 , US7005493 B2

[14] B. Smith, "Infrared Spectral Interpretation: A Systematic Approach". 1999: CRC Press, New York.

[15] R. Aaron, G. Wheeler, O. Trapp, and N.Z. Richard, "Electroosmotic flow in a poly(dimethylsiloxane) channel does not depend on percent curing agent". Electrophoresis 2004. 25(7-8): pp. 1120-1124.

[16] D.F. Stamatialis, N. Stafie, K.Buadu, M. Hempenius, and M. Wessling, "Observations on the permeation performance of solvent resistant nanofiltration membranes". Journal of Membrane Science, 2006. 279(1-2): pp. 424-433.

[17] Y. Junzhi and Y.S. David, "Synthesis of an organosilicon hyperbranched oligomer containing alkenyl and silyl hydride groups". Journal of Polymer Science Part A: Polymer Chemistry, 1999. 37(20): pp. 3778-3784.

[18] D.J. Campbell, K.J. Beckman, C.E. Calderon, P.W. Doolan, R.H. Moore, A.B. Ellis, and G.C. Lisensky, "Uses of polydimethylsiloxane (PDMS) elastomer replication and compression of bulk surface structures with polydimethylsiloxane elastomer". Journal of Chemical Education, 1999. 76.
[19] S.J. Lue, C.L. Tsai, D. Lee, K.P.O. Mahesh, M. Hua, C. Hu,Y. Jean,K. Lee, and J.-Y. Lai, "Sorption, diffusion, and perm-selectivity of toluene vapor/nitrogen mixtures through polydimethylsiloxane membranes with two crosslinker densities". Journal of Membrane Science, 2010. 349(1-2): pp. 321-332.

[20] G. Qunhui, H. Ohya, and Y. Negishi, "Investigation of the permselectivity of chitosan membrane used in pervaporation separation II. Influences of temperature and membrane thickness". Journal of Membrane Science, 1995. 98(3): pp. 223-232.

[21] N. Stafie, D.F. Stamatialis, and M. Wessling, "Effect of PDMS cross-linking degree on the permeation performance of PAN/PDMS composite nanofiltration membranes". Separation and Purification Technology, 2005. 45(3): pp. 220-231.

[22] J.G. Villaluenga and A. Tabe-Mohammadi, "A review on the separation of benzene/cyclohexane mixtures by pervaporation processes". Journal of Membrane Science, 2000. 169(2): pp. 159-174.

[23] X.Feng and R.Y.M. Huang, Liquid Separation by Membrane Pervaporation: "A Review. Industrial \& Engineering Chemistry Research", 1997. 36(4): pp. 1048-1066.

[24] J.G.Wijmans and R.W. Baker, "The solutiondiffusion model: a review". Journal of Membrane Science, 1995. 107(1-2): pp. 1-21.

[25] Q.T. Nguyen, Z. Bendjama, R. Clément, and Z. Ping, "Poly(dimethylsiloxane) crosslinked in different conditions.Part I. Sorption properties in water-ethyl acetate mixtures. Phys". Chem. Chem. Phys, 1999. 1(3): p. pp. 2761-2766.

[26] Q.T. Nguyen, Z. Bendjama, R. Clément, and Z. Ping, "Poly(dimethylsiloxane) crosslinked in different conditions". Part II. Pervaporation of water-ethyl acetate mixtures. Phys. Chem. Chem. Phys, 2000. 2(3): pp. 395-400. 
التحقيق من تأثير نسبة التثابك في بوليمرات ثنائي ميثيل بولي سيلوكسان علي إنتقائية أغثية الفصل

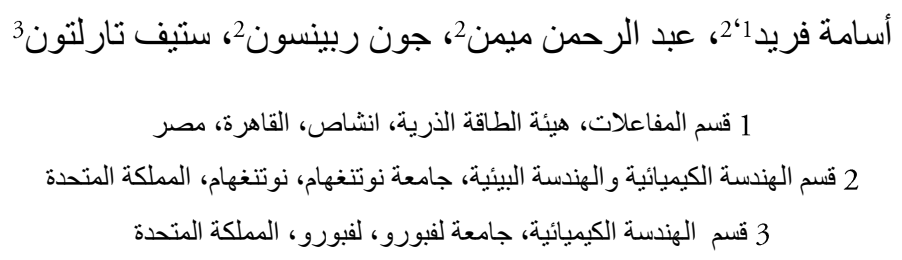

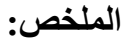

نسبة التثابك في البوليمرات لها أهية كبيرة في التعديل الثبكي للبوليمرات ذي الصلة ومن ثم أداء الأغثية واستقرارها. وقد ركز هذا البحث على التحقيق في تأثير الامنصاص على إنتقائية الغثاء من حيث قياس تمدد بوليمر ات ثنائي ميثيل بولي سيلوكسان في محلول الكحول / الدياه. وقد تم الحصول على أطياف بوليمر ات ثنائي ميثيل بولي سيلوكسان مختلفة باستخدام مطياف نيكوليه وتحديد تركيز الدذيب بواسطة معامل الإنكسار. وقد تبين من النتائج التجريبية أن درجة تمدد البوليمرات انخفضت مع زيادة نسبة التثابك المحتوى، مما أدى إلى تحول هيكل الثبكة البوليمر الي أكثر جمودا مما أدى إلى تقليل حجم وحرية حركة للجزئيات واتبعها كذلك انخفاض كمية استيعابها للسائل في البوليم. أدت زيادة التشابك الي الحد من قدرة البوليمر اللامائية على الامتصاص ـ وقد وجد أن على كل درجات التشابك كانت الإنتقائية نحو الإيثانول و الأيزوبروبانول من المحلول المائي. و أثتبت التجارب أن معامل الامتصاص للإيزوبروبانول أعلى من الإيثانول في جميع محتويات التشابك، وأن زيادة محتوى التشابك أدى إلى زيادة معامل الامتصاص. 